\title{
Mechanical strength of wheat grain varieties influenced by moisture content and loading rate
}

\author{
Yaoming $\mathrm{Li}^{1}$, Farman Ali Chandio ${ }^{1,2^{*}}$, Zheng $\mathrm{Ma}^{1}$, Imran Ali Lakhiar ${ }^{1}$, Abdul Razaque Sahito ${ }^{3}$, \\ Fiaz Ahmad ${ }^{4}$, Irshad Ali Mari², Umer Farooq ${ }^{5}$, Muhammad Suleman ${ }^{5}$ \\ (1. Jiangsu University, School of Agricultural Equipment Engineering, Zhenjiang 212013, Jiangsu, China; \\ 2. Sindh Agriculture University, Faculty of Agricultural Engineering, Tandojam, Sindh, Pakistan; \\ 3. Institute of Environmental Engineering and Management, MUET, Jamshoro, Pakistan; \\ 4. Department of Agricultural Engineering, Bahaudin Zakaria University, Multan, Pakistan; \\ 5. Department of Mathematics, COMSATS University, Islamabad, Pakistan)
}

\begin{abstract}
Mechanical shear resistance of wheat grain is a significant concern for the designers and researchers related to the design of threshing, handling and processing machinery of the field crops. The grain mechanical properties directly affect the machine geometry and its operational parameters. The present study was carried out to determine the shear resistance of five wheat varieties (Locally names; TD-02, Sindhu-1105, Benazir, China and SKD-118) influenced by moisture content (16.7\%, $18.7 \%$ and $19.5 \%$ ) and loading rate $(3 \mathrm{~mm} / \mathrm{s}, 6 \mathrm{~mm} / \mathrm{s}$ and $9 \mathrm{~mm} / \mathrm{s}$ ). However, some physio-dimensional properties (length, width, thickness, slenderness ratio, surface area and sphericity) were obtained at different moisture contents. The results showed that the shear resistance reduced by increasing the moisture content and loading rate. The average shear resistance decreased from $10.45 \mathrm{~N}$ to $3.74 \mathrm{~N}$ for $3-9 \mathrm{~mm} / \mathrm{s}$ loading rate at moisture content of $16.7 \%$ to $19.5 \%$. Thus, the maximum correlation $(r=0.905)$ of shear resistance obtained at $16.7 \%$, whereas minimum correlation $(r=0.692)$ obtained at $19.5 \%$. The shear resistance of wheat grain was highly significant $(p<0.05)$ at $9 \mathrm{~mm} / \mathrm{s}$ for $19.5 \%$. Shear resistance decreased with an increase in the moisture content in the grain whereas deformation is increasing with the increase of moisture content. However, the maximum bulk density of wheat grain obtained at $19.5 \%$ for SKD- 118 , while the minimum obtained at $16.7 \%$ for TD-02. It is recommended that the design and modification of wheat grain processing equipment should be executed on the physio-mechanical properties of grain varieties.
\end{abstract}

Keywords: wheat grain, shear resistance, bulk density of grain varieties, moisture content, loading rates DOI: $10.25165 /$ j.ijabe.20181104.3737

Citation: Li Y M, Chandio F A, Ma Z, Lakhiar I A, Sahito A R, Ahmad F, et al. Mechanical strength of wheat grain varieties influenced by moisture content and loading rate. Int J Agric \& Biol Eng, 2018; 11(4): 52-57.

\section{Introduction}

Wheat grain is a substantial source of energy throughout the world for human beings. Grains of rice, wheat, and maize provide the essential nutrients for a human nature in the world. Average annual consumption of cereal grains is $131 \mathrm{~kg} /$ capita, which consist of $108 \mathrm{~kg}$ of wheat per capita in Europe. While in Asia, rice is

Received date: 2017-07-04 Accepted date: 2018-04-03

Biographies: Yaoming Li, PhD, Professor, research interests: design and research of modern agricultural machinery, Email: ymli@ujs.edu.cn; Zheng Ma, $\mathrm{PhD}$, Assistant Researcher, research interests: design and research of modern agricultural machinery, Email: mazheng123@ujs.edu.cn; Imran Ali Lakhiar, $\mathrm{PhD}$ Scholar, research interests: soil and water conservation, Email: 5103160321@stmail.ujs.edu.cn; Abdul Razaque Sahito, PhD, Associate Professor, research interests: soil and environmental engineering, Email: ar.sahito@faculty.muet.edu.pk; Fiaz Ahmad, PhD, Assistant Professor, research interests: mechanization engineering, Email: fiazahmad@bzu.edu.pk; Irshad Ali Mari, PhD, Assistant Professor, research interests: mechanization engineering, Email: irshad mari@hotmail.com; Umer Farooq, PhD, Assistant Professor, research interests: fluid engineering and mathematics, Email: umer farooq@, comsats.edu.pk; Muhammad Suleman, PhD, Assistant Professor, research interests: fluid machinery and mathematics, Email: muhammadsuleman@, vcomsats.edu.pk

*Corresponding Author: Farman Ali Chandio, Post-Doc Fellow, research interests: design of modern agricultural machinery. Jiangsu University, School of Agricultural Equipment Engineering, Zhenjiang 212013, Jiangsu, China. Tel: +86-15751017175, Email: farman_chandio@hotmail.com. half of the annual cereal consumption ${ }^{[1]}$. Mechanical properties of agricultural seeds need an appropriate design of agrarian processing machines, but its specific application should be understood before determining them experimentally ${ }^{[2]}$. Thus, physio-mechanical characteristics have been influenced by various elements such as length, width, size, moisture content and the speed of blade during the harvesting of cereal crops.

Furthermore, the information of mechanical properties of grains is imperious for standard designing of proficient grain harvesting, cleaning and handling and crushing processes. During the accumulation and threshing operation by the harvesting/threshing machinery grain damage is a significant factor which affects the efficiency of the harvesting machinery. Ultimately, this grain damage leads to decrease the quality of harvested grains and further changes the storage life. During the cleaning processes of grains, mechanical properties also influenced the design of the sieves and straw walkers. Regarding the milling production, we need ground raw materials to accelerate the technological phase, to obtain a commercialized product ${ }^{[3]}$. Crushing is very significant in wheat processing and decides on the degree of fineness, particle size distribution and effect on mechanical strength for final products of wheat grains. The wheat flour milling is a gradual reduction process ${ }^{[4]}$. Crushing is applied to accomplish the physical disentanglement of every single component while sieving fractionates the millings by particle size 
and density of enriched segments. However, precisely, when particles vary in thickness and particle size, a specific component is limited in the accomplished final purity ${ }^{[5,6]}$

Cereal grain is a granular material, which demonstrates different mechanical behavior to liquids and solids. The mechanical properties of grain settling depend on the properties of the single grain, load history, resistance between particles and inter-particle connected geometrically. Grain as a material of biological origin reveals the strong dependence ${ }^{[6]}$ of its stress-strain behavior on the moisture content affecting the properties of the seed coat as well as of the endosperm of single grain under standard operating load ${ }^{[7]}$. Knowledge of mechanical properties of cereals improves the process, comprising materials within the food industries ${ }^{[8]}$. The flow of grain is found expensive and time-consuming when investigated grain experimentally on a large scale $^{[9]}$.

The interest in how mechanical forces can influence on the mechanical and physic-biological structure at the variation of level in plant ${ }^{[10]}$ seed (hardness) science ${ }^{[11,12]}$. Grain milling process for the preferred to separation depends on the distinct mechanical properties of the wheat grain and their adhesive forces ${ }^{[13,14]}$. In spite of all these and many others efforts made by researchers who studied the physical and mechanical characteristics in such environment but still their work is not adequate to enlighten all aspects of wheat grain varieties relation between loading and moisture contents for thrashing and processing industries. It is the hypothesis that the better understanding of shear resistance (Four Pakistani wheat varieties and one China hybrid variety cultivated in Sindh, province, Pakistan) helps to decrease the grain damage at the threshing level and also be helpful during the processing phases at different moisture levels. Keeping in view all these aspects, the present study was proposed to determine the shear resistance of wheat grain varieties influenced by moisture content and loading rate.

\section{Materials and methods}

\subsection{Experiment setup}

The present research was carried out at Food Science Research Laboratory, Sindh Agriculture University, Tandojam, Pakistan, during the year 2017. The wheat grains of five different varieties cultivated in Sindh- Pakistan (TD-02, Sindhu-1105, Benazir, China and SKD-118) obtained from Agriculture Research Centre, Tandojam, Sindh, at the harvesting time than put into polyethylene bags and wrapped tightly for further processing.

Wheat grain samples were initially prepared from the harvesting to storage (Moisture ranged from $9.3 \%$ to $41.5 \%$ for wheat grains ${ }^{[15]}$. The moisture content of grain was examined on $16.7 \%, 18.7 \%$ and $19.5 \%( \pm 0.2 \%)$. The initial moisture content of grain samples was measured by digital grain moisture meter and kept constant throughout the experiment. The wrapped sample of grain was preservedfor the uniform distribution of moisture for $48 \mathrm{~h}$. To maintain the moisture level of the grain, distilled water was added to samples accordingly ${ }^{[16,17]}$. The following equation expresses the mathematical form of the addition of water in wheat grain:

$$
Q=\frac{W_{i}\left(M_{a}-M_{b}\right)}{100-M_{a}}
$$

where, $Q$ is moisture content of wheat grain, $\% ; W_{i}$ is initial mass of grains, $\mathrm{kg} ; M_{a}$ is initial moisture content of grains, $\% ; M_{b}$ is final moisture content of grains, $\%$
The bulk density of wheat grain varieties determined by filling a predefined container, striking the top level and then weighing the constants ${ }^{[18,19]}$. Before experiment, grains (mature and sound) were randomly selected from the samples and separated from husk or outer covering of seed manually.

\subsection{Physio-dimensional properties of wheat grain}

The basic dimensions (width, thickness, length, sphericity, and surface area) were measured before each test at various moisture content levels $(16.7 \%, 18.7 \%$, and 19.5\%). The length; width and thickness of grains were measured by digital vernier caliper. Slenderness ratio; geometric mean and sphericity were calculated. The slenderness ratio of wheat grain was calculated by given expression $^{[2]}$

$$
S=\frac{L}{W}
$$

Grain surface area was calculated by given expression respectively ${ }^{[2,20]}$

$$
\begin{gathered}
S=\frac{\Omega B L^{2}}{(2 L-B)} \\
B=\sqrt{W T}
\end{gathered}
$$

The sphericity $(\varphi)$ defined as the ratio of the surface area of the sphere having the same volume as that of the grain to the surface area of the grain was determined using ${ }^{[2,20]}$

$$
\varphi=\frac{(L W T)^{1 / 3}}{L}
$$

where, $L, W, T$ are length, width and thickness of wheat grains, $\mathrm{mm}$.

\subsection{Test equipment}

The shear test performed by LFRA texture analyzer machine with a computer program for data acquisition / direct data display (TMS-Pro computer-controlled texture measurement system with attached load cell range up to $500 \mathrm{~N}$ for accuracy $5 \%$ and resolution $5 \mathrm{~N}$ ) was used to measure the shear resistance of wheat grains.

\subsection{Shear test}

Shear test of the grains was performed using the shear test apparatus at moisture content levels of $16.7 \%, 18.7 \%$ and $19.5 \%$ respectively and at three loading rates $(3 \mathrm{~mm} / \mathrm{s}, 6 \mathrm{~mm} / \mathrm{s}$ and $9 \mathrm{~mm} / \mathrm{s})$. Specimens were placed at a central and horizontal position between rounded metallic support having $60 \mathrm{~mm}$ distance from upper to lower regime and load applied on a vertically movable plate attached to the fabricated blade (Figure 1). A central slot allows free movement of the blade to limit friction during the analysis. Shear resistance was recorded during the deformation process.
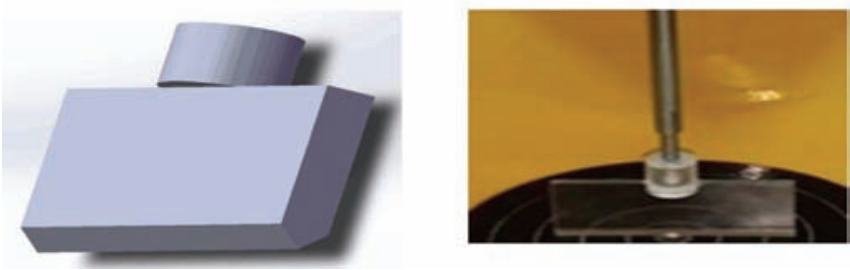

Figure 1 Thematic view of fabricated loading blade

\subsection{Statistical analysis}

The present research was laid out on a factorial statistical design. 135 treatments (5 wheat grain varieties, 3 moisture content and 3 loading rates) were assessed on the RCBD (randomized complete blocks design) and were replicated five times. All data was statistically analyzed for various parameters 
of study at different moisture contents and loading rate by SPSS program. Duncan's multiple comparisons were used to determine the difference existing at a $5 \%$ level of significance.

\section{Results and discussion}

The results of variance analysis (ANOVA) indicating moisture, variety, and loading variables on the shear resistance of wheat grains are presented in Table 1. Furthermore, interaction effects of moisture content $\times$ loading variable, moisture content $\times$ variety, loading variable $\times$ variety and moisture content $\times$ loading variable $x$ variety on shear resistance found significant. The variance analysis of the data indicated that the shear resistance of wheat grains was highly significant $(p<0.05)$ at higher loading $(9 \mathrm{~mm} / \mathrm{s})$ variable and moisture $(19.5 \%)$ variable. The effect of moisture contents on physio-dimensional was not significant $(p<0.05)$ from each other for moisture contents.

Table 1 Results of analyses of variance indicating the effect of varieties, moisture contents and Loading rate for the shear resistance of wheat grains

\begin{tabular}{|c|c|c|c|c|c|}
\hline Source & $\mathrm{DF}$ & Sum of the square (SS) & Mean Square (MS) & $F$-value & Probability $(P)$ \\
\hline Moisture & 2 & 77.996 & 38.998 & 50.74 & $0.0000^{* *}$ \\
\hline Varieties & 4 & 68.813 & 17.203 & 22.38 & $0.0000^{* *}$ \\
\hline Moisture $\times$ Loading & 4 & 14.062 & 3.516 & 4.57 & $0.0021 * *$ \\
\hline Moisture $\times$ Variety & 8 & 19.823 & 2.478 & 3.22 & $0.0029 * *$ \\
\hline Loading $\times$ Variety & 8 & 17.966 & 2.246 & 2.92 & $0.0060^{* *}$ \\
\hline Moisture $\times$ Loading $\times$ Variety & 16 & 22.784 & 1.424 & 1.85 & $0.0359 * *$ \\
\hline Error & 90 & 69.167 & 0.769 & & \\
\hline
\end{tabular}

Note: ** Significant at 0.05 levels.

\subsection{Physio-dimensional properties of wheat grain:}

Essential physio-dimensional properties (length, width, thickness, slenderness ratio, surface area and sphericity) of wheat grains at $16.7 \%, 18.7 \%$, and $19.5 \%$ were measured (Table 2). The highest length, width, thickness, slenderness ratio obtained towards Benazir variety at $19.5 \%$, while lowest observed for TD-02 at
$16.7 \%$. Highiest surface area and sphericity of wheat grain were seen for TD-02 at 19.5\%, whereas minimum found for TD-02 at $16.7 \%$ followed by grain varieties. We revealed that highest moisture content provides flexibility and elasticity to grain varieties during deformation. Whereas $a, b$, and $c$, indicates that dimensions are significantly different $(p>0.05)$.

Table 2 Effects of moisture contents on length, width, thickness, slenderness ratio, surface area and sphericity of wheat grain

\begin{tabular}{cccccccc}
\hline Varieties & Moisture content/\% & Length/mm & Width/mm & Thickness $/ \mathrm{mm}$ & Slenderness ratio & S.A/mm & Sphericity/\% \\
\hline TD-02 & 16.7 & $6.2^{\mathrm{c}}$ & $3.0^{\mathrm{c}}$ & $2.7^{\mathrm{c}}$ & $2.0^{\mathrm{c}}$ & $34.07^{\mathrm{c}}$ & $59^{\mathrm{c}}$ \\
TD-02 & 18.7 & $6.4^{\mathrm{b}}$ & $3.4^{\mathrm{b}}$ & $3.0^{\mathrm{b}}$ & $1.8^{\mathrm{b}}$ & $42.62^{\mathrm{b}}$ & $62^{\mathrm{b}}$ \\
TD-02 & 19.5 & $6.4^{\mathrm{a}}$ & $3.3^{\mathrm{a}}$ & $3.0^{\mathrm{a}}$ & $1.9^{\mathrm{a}}$ & $45.32^{\mathrm{a}}$ & $62^{\mathrm{a}}$ \\
Sindhu-1105 & 16.7 & $5.98^{\mathrm{a}}$ & $3.1^{\mathrm{a}}$ & $2.8^{\mathrm{a}}$ & $1.9^{\mathrm{a}}$ & $36.59^{\mathrm{a}}$ & $62^{\mathrm{b}}$ \\
Sindhu-1105 & 18.7 & $6.13^{\mathrm{b}}$ & $3.2^{\mathrm{c}}$ & $2.8^{\mathrm{a}}$ & $1.9^{\mathrm{ab}}$ & $38.04^{\mathrm{a}}$ & $61^{\mathrm{a}}$ \\
Sindhu-1105 & 19.5 & $6.2^{\mathrm{a}}$ & $2.9^{\mathrm{a}}$ & $2.8^{\mathrm{a}}$ & $2.1^{\mathrm{b}}$ & $35.35^{\mathrm{b}}$ & $59^{\mathrm{b}}$ \\
Benazir & 16.7 & $7.0^{\mathrm{a}}$ & $3.4^{\mathrm{a}}$ & $2.9^{\mathrm{a}}$ & $2.0^{\mathrm{b}}$ & $44.48^{\mathrm{a}}$ & $58^{\mathrm{b}}$ \\
Benazir & 18.7 & $6.9^{\mathrm{a}}$ & $3.3^{\mathrm{b}}$ & $2.7^{\mathrm{a}}$ & $2.0^{\mathrm{a}}$ & $41.17^{\mathrm{a}}$ & $57^{\mathrm{a}}$ \\
Benazir & 19.5 & $7.0^{\mathrm{b}}$ & $3.4^{\mathrm{ab}}$ & $2.9^{\mathrm{ab}}$ & $2.0^{\mathrm{a}}$ & $35.27^{\mathrm{b}}$ & $58^{\mathrm{ab}}$ \\
China & 16.7 & $6.5^{\mathrm{a}}$ & $3.0^{\mathrm{b}}$ & $2.5^{\mathrm{a}}$ & $2.1^{\mathrm{a}}$ & $35.26^{\mathrm{a}}$ & $56^{\mathrm{b}}$ \\
China & 18.7 & $5.9^{\mathrm{a}}$ & $3.1^{\mathrm{b}}$ & $2.7^{\mathrm{a}}$ & $1.9^{\mathrm{ab}}$ & $35.45^{\mathrm{b}}$ & $62^{\mathrm{c}}$ \\
China & 19.5 & $6.4^{\mathrm{b}}$ & $3.0^{\mathrm{c}}$ & $2.6^{\mathrm{a}}$ & $2.1^{\mathrm{b}}$ & $35.84^{\mathrm{a}}$ & $57 \mathrm{a}$ \\
SKD-118 & 16.7 & $6.7^{\mathrm{ab}}$ & $3.0^{\mathrm{b}}$ & $2.5^{\mathrm{a}}$ & $2.2^{\mathrm{ab}}$ & $36.06^{\mathrm{a}}$ & $55^{\mathrm{b}}$ \\
SKD-118 & 18.7 & $6.6^{\mathrm{a}}$ & $3.0^{\mathrm{a}}$ & $2.7^{\mathrm{a}}$ & $2.2^{\mathrm{b}}$ & $37.49^{\mathrm{a}}$ & $57^{\mathrm{b}}$ \\
SKD-118 & 19.5 & $6.7^{\mathrm{a}}$ & $3.1^{\mathrm{a}}$ & $2.7^{\mathrm{a}}$ & $2.1^{\mathrm{b}}$ & $38.75^{\mathrm{a}}$ \\
\hline
\end{tabular}

Note: Different letters indicates that in a column are significantly different $(p>0.05)$ by Duncan's multiple ranges of the test.

3.2 Effects of moisture contents $(16.7 \%, 18.7 \%$ and $19.5 \%)$ on shear resistance

Shear resistance of wheat grain varieties (TD-02, Sindhu-1108, Benazir, China and SKD-118) at loading $(3 \mathrm{~mm} / \mathrm{s}, 6 \mathrm{~mm} / \mathrm{s}$ and $9 \mathrm{~mm} / \mathrm{s})$ with moisture contents $(16.7 \%, 18.7 \%$ and $19.5 \%)$ on are presented in Figures 2-4. The shear resistance of wheat grains varied in $10.45-4.75 \mathrm{~N}, 8.33-3.98 \mathrm{~N}$ and $7.42-3.74 \mathrm{~N}$ at $3 \mathrm{~mm} / \mathrm{s}$, $6 \mathrm{~mm} / \mathrm{s}$ and $9 \mathrm{~mm} / \mathrm{s}$ respectively for TD-02, Sindhu-1108, Benazir, China and SKD-118 on moisture contents, respectively. Maximum correlation $(r=0.905)$ of shear resistance obtained at $16.7 \%$, whereas, minimum correlation $(r=0.692)$ obtained at $19.5 \%$.

$$
S R=-0.3996(W . V \cdot L . S)+10.912, \quad R^{2}=0.9058
$$

Figure 2 demonstrates that the maximum shear resistance $(10.45 \mathrm{~N})$ of wheat grain obtained for $16.7 \%$ at $3 \mathrm{~mm} / \mathrm{s}$. Whereas, the minimum shear resistance $(3.74 \mathrm{~N})$ obtained for $19.5 \%$ keeping load at $9 \mathrm{~mm} / \mathrm{s}$. The obtained results in complete agreement with Bagheri et al. ${ }^{[21]}$ The maximum rupture force was accomplished at $(8 \%)$ and $10 \mathrm{~mm} / \mathrm{min}$; whereas the lowest rupture force corresponded to the $(14 \%)$ and $10 \mathrm{~mm} / \mathrm{min}$ at brown rice varieties. similarly, the maximum rupture force was obtained at the minimum level of moisture contents for cumin seeds ${ }^{[14,22]}$. Hypothetically, the maximum surface area of grain expected for maximum shear resistance but our results revealed that it might be affected by some 
physio-mechanical and textural characteristics of grains.

$$
S . R=-0.0339(W . V \cdot L . S)+9.5707, \quad R^{2}=0.7769
$$

The maximum amount of moisture available in the grain results in sudden deformation and crushing in the grains with the lowest value of shear resistance.

The moisture content level increases whereas rupture force of sunflower seed decreased, rupture force decreased as loading rate increased $^{[23]}$ (Figure 3). The shear resistance of wheat grains was highly significant $(p<0.05)$ at $9 \mathrm{~mm} / \mathrm{s}$ and $19.5 \%$

$$
S R=-0.3146(W . V \cdot L . S)+8.3749, \quad R^{2}=0.6924
$$

According to Duncan's multiple range tests, the values of the shear resistance of grain at $19.5 \%$ is noticeably higher $(p<0.05)$ than $16.7 \%$ and $18.7 \%$. Duncan test showed that there were noticeable differences among the three loading speed $(p<0.05)$.

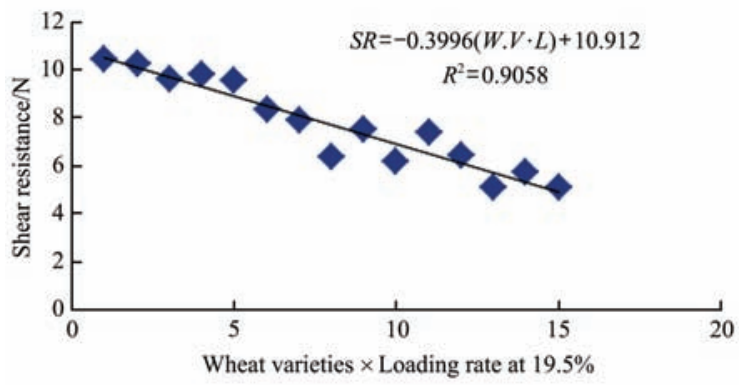

Figure 2 Interaction of wheat grain varieties and loading rates on Shear resistance towards $16.7 \%$

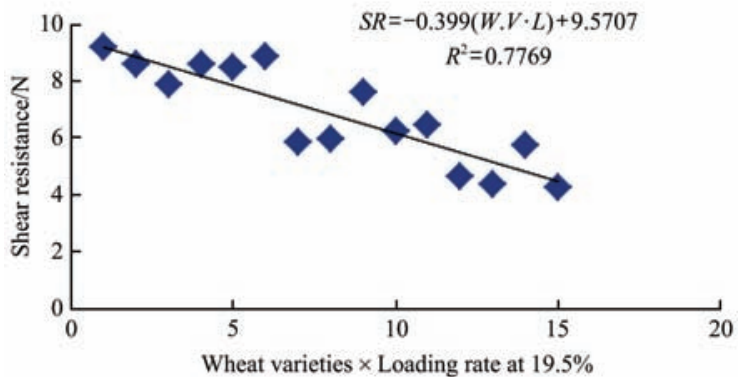

Figure 3 Effect of wheat grain varieties and loading rates on shear resistance towards $18.7 \%$

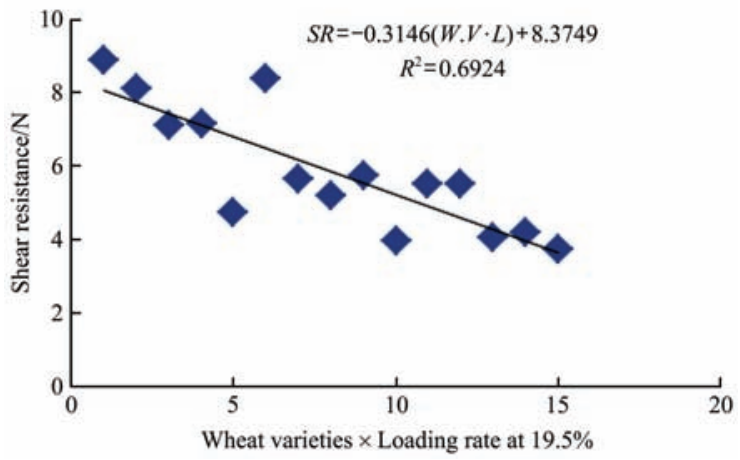

Figure 4 Interaction of wheat grain varieties and loading rates on shear resistance towards $19.5 \%$

3.3 Interaction effects of wheat grain varieties and moisture contents on the shear resistance

The results of the interaction effect of wheat grain variety and moisture contents $(16.7 \%, 18.7 \%$ and $19.5 \%)$ on the shear resistance are presented in Figure 5. The results showed that the shear resistance of wheat grain varieties varied in 8.741-7.588 N, $8.188-6.075 \mathrm{~N}, 7.031-5.687 \mathrm{~N}, 6.931-5.774 \mathrm{~N}$ and 7.702-4.495 $\mathrm{N}$ at $16.7 \%, 18.7 \%$ and $19.5 \%$, respectively. The highest shear resistance $(8.741 \mathrm{~N})$ observed for TD-02 at $16.7 \%$. Whereas, the lowest $(4.495 \mathrm{~N})$ found at $19.5 \%$ for SKD-118 variety followed by Sindhu-1108, Benazir and China, respectively.

Whereas, shear resistance increased at $16.7 \%$ and decreased at $19.5 \%$. Zoerb ${ }^{[23]}$ stated that most agrarian products are flexible throughout the initially applied load for deformation, but the increase in loading rate increases the viscoelastic properties. Moreover, increasing the moisture content from $16.7 \%$ to $19.5 \%$ trend showed shear resistance had decreased for SKD-118.The shear resistance of wheat grains is noticeably higher $(p<0.05)$ for $19.5 \%$ at TD-02. Duncan test showed noticeable $(p<0.05)$ differences among the three loading speed and wheat grain varieties.

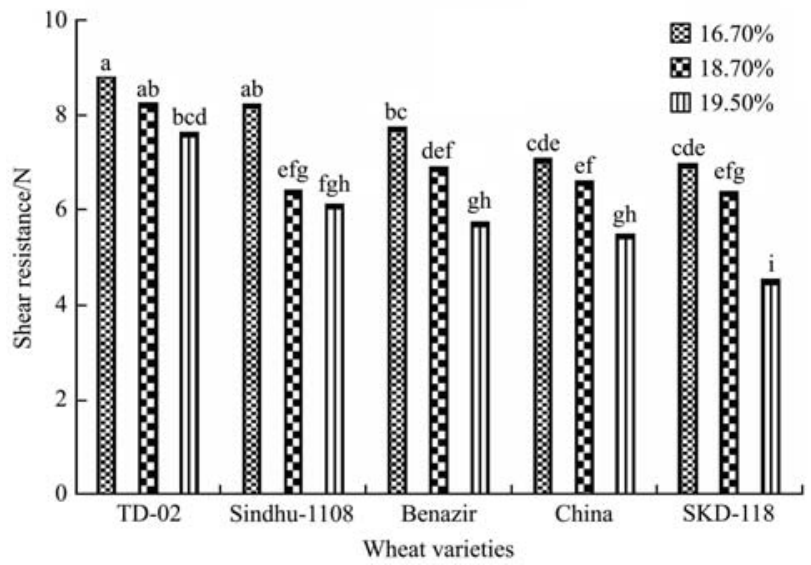

Figure 5 Interaction effects of wheat varieties (TD-02, Sindhu-1108, Benazir, China and SKD-118) and moisture contents on the shear resistance

3.4 Interaction effects of loading speeds and moisture contents on the shear resistance

The results of the interaction effect of loading variables $(3 \mathrm{~m} / \mathrm{s}$, $6 \mathrm{~m} / \mathrm{s}$ and $9 \mathrm{~m} / \mathrm{s}$ and moisture contents $(16.7 \%, 18.7 \%$, and $19.5 \%)$ on the shear resistance of wheat grain varieties is presented in Figure 6. The results showed that shear resistance varied in 7.001-9.936 N, 6.142-7.265 N and 4.433-5.954 N for $3 \mathrm{~m} / \mathrm{s}, 6 \mathrm{~m} / \mathrm{s}$ and $9 \mathrm{~m} / \mathrm{s}$ at $16.7 \%, 18.7 \%$ and $19.5 \%$, respectively. The highest shear resistance observed at $9 \mathrm{~m} / \mathrm{s}$ for $16.7 \%$, while lowest found at $9 \mathrm{~m} / \mathrm{s}$ for $19.5 \%$. The rupture force increased with the decrease in moisture content for cumin seed, asan increase in the compressive load increases the force ${ }^{[17]}$. The shear resistance of wheat grains is highly noticeable $(p<0.05)$ at $9 \mathrm{~mm} / \mathrm{s}$ for $19.5 \%$. Similarly, according to Duncan's multiple range test results showed that the values of shear resistance have significant differences $(p<0.05)$ from each other for three loading speeds and moisture contents.

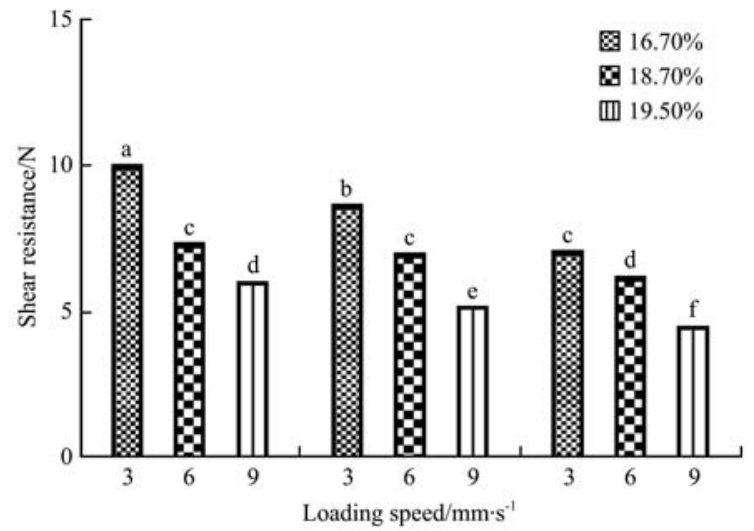

Figure 6 Interaction effects of loading and moisture contents on the shear resistance 
3.5 Interaction effect of wheat grain varieties and loading speeds on the shear resistance

The results of the interaction effects of wheat grain varieties and moisture contents $(16.7 \%, 18.7 \%$, and $19.5 \%)$ on the shear resistance (TD-02, Sindhu-1108, Benazir, China and SKD-118) are presented in Figure 7. The data indicate that shear resistance varied from 6.463-9.52 N (TD-02), 5.185-8.980 N (Sindhu-1105), 5.005-8.387 N (Benazir), 4.695-8.256 N (China) and 4.468-7.29 N (SKD-118) at $3 \mathrm{~m} / \mathrm{s}, 6 \mathrm{~m} / \mathrm{s}$ and $9 \mathrm{~m} / \mathrm{s}$, respectively. The highest shear resistance observed for TD-02 at $3 \mathrm{~m} / \mathrm{s}$ and lowest found at $9 \mathrm{~m} / \mathrm{s}$ for SKD-118 followed by Sindhu-1108, Benazir, and China, respectively. Theshear force decreased from $47.62 \mathrm{~N}$ to $13.43 \mathrm{~N}$ while loading rate increased from $2 \mathrm{~mm} / \mathrm{min}$ to $5 \mathrm{~mm} / \mathrm{min}$ for cumin seed ${ }^{[24]}$. Similar studies have been done for cucumber straw $^{[25]}$. Furthermore, increasing the loading rate from $3 \mathrm{~mm} / \mathrm{s}$ to $9 \mathrm{~mm} / \mathrm{s}$ trend showed shear resistance had increased for TD-02. The shear resistance of wheat grains is highly noticeable $(p<0.05)$ at $9 \mathrm{~mm} / \mathrm{s}$ for TD-02. Similarly, according to Duncan's multiple range test results showed that the values of shear resistance have significant differences $(p<0.05)$ from each other for three loading speed and moisture contents.

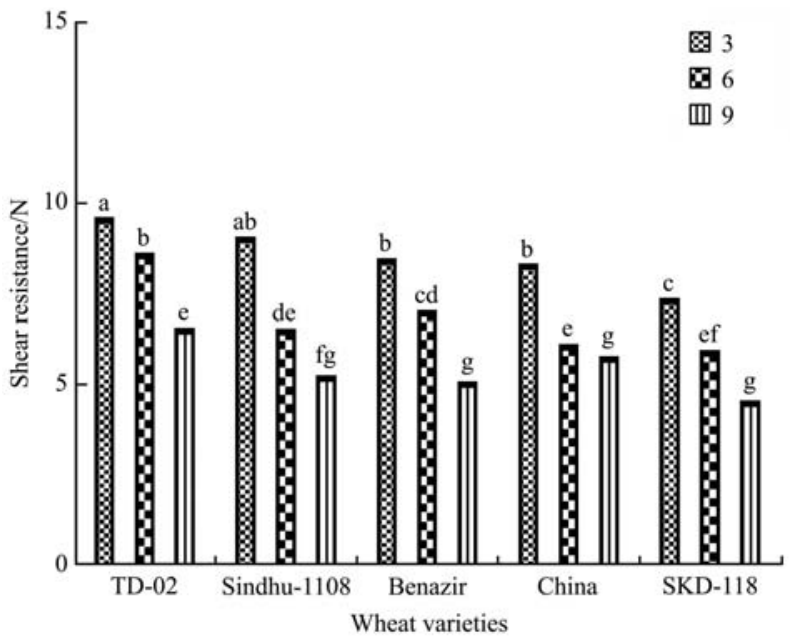

Figure 7 Interaction effect of wheat grain varieties and loading rate on the shear resistance

\subsection{Bulk density of wheat grains}

The bulk density of wheat grain varieties at moisture contents was examined and presented in Figure 8, which indicates that the bulk density increased from $798-818 \mathrm{~kg} / \mathrm{m}^{3}$ (TD-02), 796$815 \mathrm{~kg} / \mathrm{m}^{3}$ (Sindhu-1105), 792-810 kg/m $\mathrm{m}^{3}$ (Benazir), $786-800 \mathrm{~kg} / \mathrm{m}^{3}$ (China) and $781-798 \mathrm{~kg} / \mathrm{m}^{3}$ (SKD-118) for $16.7 \%, 18.7 \%$ and $19.5 \%$ respectively. The results showed that highest bulk density $\left(818 \mathrm{~kg} / \mathrm{m}^{3}\right)$ obtained for TD-02 at $19.5 \%$, whereas the lowest $\left(781 \mathrm{~kg} / \mathrm{m}^{3}\right.$ ) found at $16.7 \%$ for SKD-118 followed by Sindhu-1108, Benazir, and China respectively. Few researchs with different wheat grain varieties by Al-Mahasneh and Rababah $^{[26]}$, Kheiralipour et al. ${ }^{[27]}$, Tabatabaeefar et al. ${ }^{[29]}$ indicated similar trends, whereas the lower values of density was observed in cv. Pehlivan grain at $7.3 \%$, the higher decreased in cv. Kizıltan-91 grain at $9.8 \%$. Meanwhile density of cv. Kızlltan-91 grain was observed lowest instead of cv. Pehlivan grain. The bulk density value obtained by Tabatabaeefar et al ${ }^{[28]}$ at about $10 \%$ moisture content for wheat lower $\left(680 \mathrm{~kg} / \mathrm{m}^{3}\right)$ than that of our study $\left(720 \mathrm{~kg} / \mathrm{m}^{3}\right)$. Furthermore, increasing the moisture content of wheat grain $(p<0.05)$ decreases significantly in bulk density variations as shown in Figure 8.

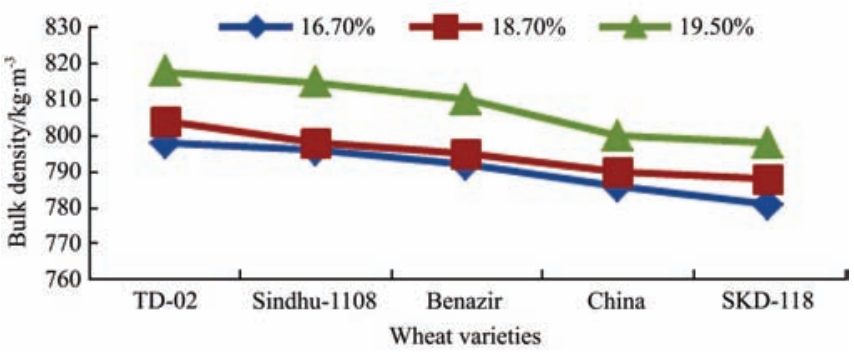

Figure 8 Bulk density of wheat grains at different moisture contents

\section{Conclusions}

The shear resistance of wheat grain varieties increases by decreasing the moisture content and loading rate $(p<0.05)$. The maximum bulk density of wheat grain varieties obtained at higher moisture content (19.5\%) for SKD-118 whereas the lowest bulk density corresponds to lower moisture content (16.7\%) for TD-02. The values of shear resistance of wheat grain varieties obtained for TD-02, Sindhu-1108, Benazir, China and SKD-118 are statistically different from each other $(p<0.05)$. The shear resistance of wheat grains is highly significant $(p<0.05)$ at higher loading $(9 \mathrm{~mm} / \mathrm{s})$ rate and moisture content (19.5\%). The highiest values of shear resistance obtained at $16.7 \%$ for TD- 02 at $3 \mathrm{~mm} / \mathrm{s}$; whereas the lowest shear resistance corresponds to $19.5 \%$ for SKD-118 at $6 \mathrm{~mm} / \mathrm{s}$. During the experiment the shear resistance at lower levels of moisture found in the form of sudden failure with less deformation; whereas at higher levels of moisture content the grain rupture found in the gradually crushing with more distortion. It is recommended that the design and adjustment of wheat grain processing equipment's must be executed on the base of shear resistance and textural properties of wheat grain varieties.

\section{Acknowledgments}

This work is financially supported by the National Key Research of Development Program of China (Grant No. 2016YFD0702004), the National Natural Science Foundation of China (Grant No.51605196), the Jiangsu Key Research and Development Program of China (Grant No.BE2016356), the Natural Science Foundation of Jiangsu Province of China (Grant No.BK20160532), the National Science Foundation for Post-doctoral Scientists of China (Grant No. 2016M591788) and Natural Science Foundation of the Higher Education Institutions of Jiangsu Province, China (Grant No.17KJB416003).

\section{[References]}

[1] Slavin J. Why whole grains are protective: biological mechanisms Proceedings of the Nutrition Society, 2003; 62(1): 129-134.

[2] Mohsenin N N. Physical properties of plant and animal materials. New York: Gordon and Breach Science Publishers, 1970.

[3] Lupu M I, Pădureanu, V. Grinding cereals. Ed. Transilvania University of Brasov, 2012; pp.133-135.

[4] Dziki D. Effect of preliminary grinding of the wheat grain on the pulverizing process. J Food Eng, 2011; 104: 585-591.

[5] Trigwell S, TennalK B, Mazumder M K, Lindquist D A. Precombustion cleaning of coal by triboelectric separation of minerals. Particulate Science and Technology, 2003; 21(4): 353-364.

[6] Wang J, Maarten M, Schutyser A I, Boom R M, Analysis of electrostatic powder charging for fractionation of foods. Inn Food Sc and Emerg Tech, 2014; 26: 360-365.

[7] Molenda M, Stasiak M. Determination of the elastic constants of cereal grains in a uniaxial Compression test. IntAgrophy, 2002; 16: 61-65.

[8] Dyduch M, Kaminski M, Lapko A, Runkiewicz L. Amendment of 
polish standard pn-89/b-03262 concrete bens for storing granular materials and silage. XI Conference on Reinforced and Prestressed Concrete Containers for Liquids and Granular Materials, SwieradowZdroj, 2000; pp.65-69.

[9] Eurocode I. Basis of design and actions on structures-Part 4: Actions in silos and tanks. European Committee for Standardization. Central Secretariat: rue de Stassart, Brussels, 1996.

[10] Boac J M, Casada M E, Maghirang R G, Harner J P. Material and interaction properties of selected grains and oilseeds for modeling discrete particles. Am Soc Agric BiolEng, 2010; 53(4): 1201-1216.

[11] Moulia B. Plant biomechanics and mechanobiology are convergent paths to flourishing interdisciplinary research. J Exp Bot, 2013; 64: 4617-4633. doi: $10.1093 / \mathrm{jxb} / \mathrm{ert} 320$

[12] Ebrahem I Z, Amer Eissa A H, Wang Y K. Vertical brush seed metering device for sweet sugar beet planter. Int J Agric Biol Eng, 2010; 3(1): $26-37$.

[13] Steinbrecher T, Leubner-Metzger G. The biomechanics of seed germination. J Exp Bot, 2016; 68: 765-783. doi: 10.1093/jxb/erw428

[14] Burton R A, Fincher G B. Evolution and development of cell walls in cereal grains. Front Plant Sci, 2014; 5: 456. doi: 10.3389/fpls.2014. 00456

[15] Al-MahasnehM A, Rababah T M. Effect of moisture content on some physical properties of green wheat. J Food Eng, 2007; 79: 1467-1473.

[16] Wang B, Li D, Wang L J, Huang Z G, Zhang L, Chen X D, Mao Z H. Effect of moisture content on the physical properties of fibered flax seed. Int J of Food Eng, 2007; 3(5): 1-11.

[17] Kara M, Turgut N, Erkmen Y, Guler I E. Determination of the coefficient of friction of some granules, 17th National Symposium on Mechanization in Agriculture, Tokat, Turkey, 1997; pp.609-614.

[18] Deshpande S O, Bal S, Ojha T P. Physical properties of soybean. J
Agric Eng Res, 1993; 56: 89-98.

[19] Paksoy M, Aydin C. Some physical Shepherd, H. and R.K. Bhardwaj, 1986. Moisture Properties of edible squash (Cucurbita pepo L.) seeds. J. Food Eng., 2004; 65: 225-231.

[20] Kara M, Turgut N, Erkmen Y, Guler I E, Determination of coefficient of friction of some granules, 17th National Symposium on Mechanization in Agriculture, Tokat, Turkey, 1997; pp.609-614.

[21] Bagheri I, Dehpour M B, Payman S H, Zareiforoush H. Rupture strength of brown rice varieties as affected by moisture dependent and loading speed, Aus j Crop Sc, 2011; 5(10): 1239-1246.

[22] Gupta R K, Das S K, Fracture resistance of sunflower seed and kernel to compressive loading, J of Food Engg, 2000; 46: 1-8.

[23] Zoerb G C. Instrumentation and measurement techniques for determining physical properties of farm products. Transactions of the ASAE, 1967; 10: 100-109, 113.

[24] Saiedirad M H, Tabatabaeefar A, Borghei A, Mirsalehi M. Badii F, Ghasemi V M. Effects of moisture content, seed size, loading speed and seed orientation on force and energy required for fracturing cumin seed (Cuminumcyminum Linn.) under quasi-static loading, J Food Eng, 2008; 86: 565-572.

[25] Xu Y F, Zhang X L, Sun X J, Wang J Z, Liu J Z, Li Z G, et al. Tensile mechanical properties of greenhouse cucumber cane. Int J Agric \& Biol Eng, 2016; 9(5): 1-8.

[26] Al-MahasnehM A, Rababah T M. Effect of moisture content on some physical properties of green wheat, J Food. Eng, 2007; 79: 1467-1473.

[27] Kheiralipour K, Karimi M, Tabatabaeefar A, Naderi M, Khoubakht G, Heidarbeigi K. Moisture-depend physical properties of wheat (Triticum aestivum L.). J of Agricu Tech, 2008; 4(1): 53-64.

[28] Tabatabaeefar A. Moisture-dependent physical properties of wheat. IAgrophys, 2003; 17: 207-211. 